UDK 373.2:004.43

Pregledni rad

Primljeno: 15.11.2018.

Revidirana verzija: 20.12 .2018 .

Odobreno za štampu:.22.12.2018.

DOI: https://doi.org/10.46630/gped.2.2018.07

\title{
RAČUNARSKE IGRE U VASPITNO-OBRAZOVNOM RADU PREDŠKOLSKIH USTANOVA
}

\begin{abstract}
Anastasija Mamutović ${ }^{1}$
Univerzitet u Nišu, Filozofski fakultet u Nišu, Departman za pedagogiju

Apstrakt: Poslednje decenije 20. veka okarakterisao je dinamičan razvoj i ekspanzija inovativnih digitalnih medija. Ovi digitalni alati sukcesivno se pojavljuju i nalaze primenu u svim domenima čovekovog života i rada, menjajući strukturu i karakter vaspitno-obrazovne delatnosti. Kako bi se pre neposredne implementacije digitalnih medija u rad predškolskih ustanova proverila njihova pedagoška vrednost neprestano se pristupa realizaciji kako teorijskih, tako i empirijskih istraživanja. Cilj istraživačkih studija jeste dolaženje do naučnih podataka koji će biti u službi razvoja dece predškolskog uzrasta i unapređivanja nivoa njihove digitalne pismenosti. Cilj ovog rada je da se ukaže na vaspitnoobrazovni potencijal računarskih igara u radu sa decom predškolskog uzrasta uz teorijsku analizu efekata digitalnih medija na razvoj, ponašanje i učenje. Takođe se razmatraju polarizovana gledišta brojnih autora i navodi argumentacija koja se nalazi u osnovi njihovih stavova. Rezultati teorijske analize ukazuju na neophodnost kontinuiranog ispitivanja tematike edukativnih računarskih igara i njihovih pedagoških potencijala, posebno na našem području koje i dalje ima konzervativan pristup kada je u pitanju inoviranje vaspitno-obrazovnog rada primenom modernih digitalnih medija.
\end{abstract}

Ključne reči: računarske igre, predškolske ustanove, vaspitno-obrazovni rad.

\section{Uvod}

Savremeno društvo odlikuje masovna upotreba digitalnih medija u svim oblastima svakodnevnog života i rada, a digitalna pismenost zauzima primat nad opštom pismenošću. U pogledu značaja za dečiji razvoj, ponašanje i učenje izdvajaju se

\footnotetext{
${ }^{1}$ anastasija.mamutovic@filfak.ni.ac.rs
} 
računarske igre, kada je reč o savremenim digitalnim medijima. Njihova pedagoška vrednost ispoljava se u mogućnostima uvažavanja individualnih karakteristika, tempa napredovanja i personalnih interesovanja dece ranog uzrasta. Tačnije, svako dete se može opredeliti za neku od brojnih vrsta računarskih igara (akcione, avanturističke, funkcionalne i sl.), a nakon toga etape računarskih igara koje je potrebno savladati prilagoditi sopstvenom tempu napredovanja. Funkcionalnost računarskih igara ogleda se njihovoj polivalentnoj funkciji i inkorporiranju edukativnih elemenata u rad predškolskih ustanova. Kao i svaki instrument i alat učenja tako i računarske igre nužno moraju biti podvrgnute profesionalnoj proceni stručnjaka. Neadekvatna primena može osiromašiti druge razvojno značajne aktivnosti u predškolskoj ustanovi kao što su interakcija, komunikacija i igra dece ranog uzrasta.

Kompetencije vaspitača za upotrebu računarskih igara podrazmevaju njihovu pripremljenost da izaberu one koje će biti usaglašene sa ciljevima i ishodima učenja u predškolskoj ustanovi, da adekvatno odrede vreme koje je poželjno odvojiti za igranje u režimu rada i da naposletku usklade svoje stavove o upotrebi računarskih igara sa roditeljima dece. Nastojanja vaspitača da iskoriste edukativni potencijal računarskih igara neće biti od koristi ukoliko porodični ambijent ne odlikuje istovetan način primene u pogledu vrsta igara koje se deci nude i vremena provedenog pri upotrebi.

\section{Vaspitno-obrazovni značaj računarskih igara}

Uticaj novih tehnologija i računara na oblast obrazovanja (Pavlović i MihajlovProkopović, 2015) i svakodnevni život i rad (Vasiljevic i sar., 2015) nesumljivo raste tokom poslednjih nekoliko decenija (Vandewater, 2007). Digitalni mediji otvaraju brojne mogućnosti za poboljšanje prakse predškolskog vaspitno-obrazovnog rada (Mikelić-Preradović i sar., 2016). Iako se računarske igre najčešće doživljavaju kao sredstvo zabave i razonode, veoma je važno u kontekstu predškolskog vaspitanja i obrazovanja doživeti ih kao korisne alate učenja. Promena percepcije digitalnih alata pomaže u dizajniranju boljih i edukativnih računarskih igara, a sa druge strane omogućava njihovo korišćenje kao medijuma u procesu konstrukcije znanja (Prensky, 2007). Igranje računarskih i video-igara postaje najdominantniji izbor aktivnosti u slobodnom vremenu dece predškolskog uzrsta (Cherney \& London, 2006). Stručnjaci u domenu obrazovanja sve češće ističu računare kao veoma vredne alate kreativne produkcije koji mogu ispoljiti svoj edukativni potencijal u vaspitno-obrazovnom radu sa decom ranog uzrasta. U susret poverenju stručnjaka idu i rezultati istraživanja koji pokazuju da novi mediji mogu podržati razvoj mišljenja najvišeg reda i da računarske igre poseduju kapacitete da potpomognu postizanje vaspitno-obrazovnih ciljeva (Clements, 2002). Međutim, potencijali kojima raspolažu informacione tehnologije još uvek nisu na pravi način dokazani i u dovoljnoj meri iskorišćeni u obrazovanju na našim prostorima (Radovanović i Karić, 2011). Vaspitno-obrazovni značaj računarskih igara ogleda se u činjenici da one predstavljaju medijume $u$ procesu konstrukcije znanja dece predškolskog uzrasta, kao i da im se sve češće 
pridaje epitet značajnog alata ili instrumenta učenja (Prensky, 2007) koji podstiče motivaciju i radoznalnost u ranom uzrastu (Papadakis, 2018). Digitalni alati, kao što su obrazovni softveri i računarske igre implementirani su u praksu i obrazovno okruženje kao korisno sredstvo koje može obogatiti postojeće resurse učenja. Međutim, vaspitači neretko uprkos tehnologizaciji vaspitno-obrazovnog okruženja održavaju postojeće načine rada umesto da IKT iskoriste za transformaciju postojeće prakse (Plowman \& Stephen, 2003).

Virtuelni svet računarskih igara u kojem deca predškolskog uzrasta odrastaju često se doživljava kao suprotan tradicionalnom svetu odrastanja u igri (Marsh, 2010). Međutim, računarske igre kao novi medij prešle su dug put kako bi se pozicionirale u svetu obrazovanja kao poželjno sredstvo koje treba upotrebiti u procesu učenja dece ranog uzrasta. Najpre, utvrđeno je da računarske igre obezbeđuju angažovanje svih čula dece u procesu sticanja znanja, razvijaju kreativnost i podstiču aktivnost pri učenju (Anđelić i Milosavljević, 2007). Takođe, računarske igre obezbeđuju usvajanje kompleksa novih informacija, dovode do razvoja strateških veština dece kroz eksperimentisanje, rasuđivanje i greške, a pored toga mogu podučavati decu na zabavan, zanimljiv, motivišući, interesantan i ohrabrujuć način (Paraskeva et al., 2010). Pošto su računarske igre definisane kao obrazovni alat, potrebno je utvrditi koji faktori mogu uticati na učenje i razvoj dece predškolskog uzrasta u igri. Takođe, igranje računarskih igara bi trebalo nadgledati, kao i svaku drugu aktivnost dece (Paraskeva et al., 2010). U zavisnosti od načina na koji se računarske igre implementiraju u rad sa decom predškolskog uzrasta njihov potencijal se može ispoljiti ili u potpunosti zaostati (Anđelić i Milosavljević, 2007).

Razvoj tehnologije utiče na promene u načinu rada predškolskih institucija, na vaspitno-obrazovne sadržaje i odnos vaspitača prema detetu. Značajno mesto među digitalnim tehnologijama kao izvorima znanja u vrtiću pripada računaru koji se u vrtićima najčešće koristi za obrazovne softvere i računarske igre. On predstavlja vezu između fizičkog iskustva koje dete stiče putem interakcije sa okolinom i rezultata prerade tog iskustva na imaginarnom svetu računara.

Vaspitno-obrazovni značaj računarskih igara ogleda se u tome što one omogućavaju detetu učenje putem istraživanja i otkrivanja, razvijaju sistematičnost, kreativnost, preciznost, strpljivost i utiču na obogaćivanje socijalne interakcije. Deca su po prirodi zainteresovana za nove digitalne alate, a posebno privlačne su za njih računarske igre. Ovi softverski alati, didaktički osmišljeni, privlačni zbog multimedijskih elemenata, uzrokuju kod dece radoznalnost, želju za istraživanjem, za kreiranjem sopstvene strategije za pobedu u igri i osećaj superiornosti i kompetentnosti posle uspešno završene računarske igre. Računarske igre pomažu deci pri usvajanju novog znanja i utvrđivanju već stečenog, pri usvajanju novih reči, omogućavaju vežbanje fine motorike i koordinacije između oka i ruke i pomažu u radu sa decom sa posebnim potrebama. Ove pogodnosti se ostvaruju u najvećoj meri zahvaljujući multimedijalnosti, hipermedijalnosti i interaktivnosti računarskih sistema (Hristov i sar., 2013). Upotreba digitalnih alata u predškolskom uzrastu najčešće se svodi na korišćenje računarskih igara za učenje i zabavu, a upravo su to načini kroz koje deca predškolskog uzrasta najviše uče. Deca vrlo lako usvajaju pravila rada na računaru, 
bilo da je reč o igranju igara, crtanju, pregledanju slika ili prvim pokušajima pisanja, odnosno korišćenja interneta (Arsović i Zlatić, 2017).

Deca predškolskog uzrasta su duboko zakoračila u korišćenje informacione tehnologije, a početna informatička znanja dete usvaja postepeno. To se ostvaruje kao logična posledica procesa u kojem se ova tehnologija upotrebljava kao didaktičko sredstvo, sredstvo izražavanja, kreativnog stvaranja, podsticanja na druge aktivnosti i kao vaspitno-obrazovno sredstvo (Anđelković, 2008).

Pripadnici savremenih pedagoških strujanja u oblasti primene računara i računarskih igara $u$ obrazovanju na ranom uzrastu naglašavaju taj segment obrazovanja, kao pravo deteta predškolskog uzrasta da stiče bogata i raznovrsna iskustva informaciono-komunikacionim tehnologijama. Mnoge zemlje su prepoznale vaspitno-obrazovni značaj modernih digitalnih alata i kao prioritet odredile neophodnost da se svoj deci, počev od veoma ranog uzrasta omogući podjednak pristup IKT-a, naročito računarima i edukativnim računarskim igrama (Veličković, 2014). Razumevanje vaspitno-obrazovnog značaja računarskih igara zahteva procenu samog sadržaja igre, kao i vremena koje deca provode igrajući se, na račun drugih razvojno značajnih aktivnosti u predškolskom periodu (Subrahmanyam et al., 2001). Dakle, edukativni značaj računarskih igara se mora posmatrati iz iste pozicije koja je ustanovljena kada su razmatrani tradicionalni vidovi odrastanja i razvoja (Verenikina et al., 2003). Uslov pravilne primene računarskih igara jeste poznavanje razvojnih karakteristika dece ranog uzrasta, kao i zadataka i sadržaja koje deca u ovom periodu mogu savladati putem računara (Peirce, 2013).

Pored pružanja razonode i zabave, računarske igre imaju obrazovni potencijal koji se ogleda u osposobljavanju dece predškolskog uzrasta da rešavaju probleme primenom računara i razvijaju potrebne veštine (Griffiths, 2002). Vaspitno-obrazovni značaj računarskih igara ispoljava se naročito u domenu socijalnog razvoja. Naime, u predškolskoj ustanovi računar najčešće koristi grupa od par vršnjaka koji međusobno pomažu jedni drugima, razmenjuju iskustva i uče jedni od drugih kroz verbalne instrukcije i demostraciju pravilne upotrebe (Clements et al., 1993).

\section{Računarske igre i razvoj dece predškolskog uzrsta}

Pre dvadeset godina razvijanje računarskih igara je bilo veoma kompleksno. Nije bilo moguće kreirati računarsku igru bez jakih računara, skupih grafičkih kartica i na kraju dobrih programera. Danas je to potpuno drugačije, a broj edukativnih računarskih igara neprestano raste (Savanović et al., 2016). Razvoj novih tehnologija i sve značajnije prisustvo interneta u svakodnevnom životu, rezultirali su stvaranjem novog termina koji se koristi. U pitanju je termin „novi mediji”. Na svim nivoima obrazovanja uvode se nove informaciono-komunikacione tehnologije i mediji i to ne samo u pedagoškom smislu, već i kao nenastavna, logistička i administrativna podrška (Andevski i Arsenijević, 2011). Savremene generacije predškolaca koje odrastaju u sajber-svetu (Wu et al., 2014; Nikolopoulou et al., 2010) okružena brojnim produktima tehnologije digitalnog doba (Prensky, 2001) nose epitet ,internet gene- 
racija“; „urođenih govornika digitalnog jezika računara, interneta i kompjuterskih igara“" (Prensky, 2001) i „odraslih u medijima“" (Rideout, 2003). Tipično dete ranog uzrasta danas ima olakšan pristup računarskim igrama, sajtovima, video-zapisima i elektronskim pričama koji su specijalno dizajnirani za razvojni stadijum predškolaca (Cingel \& Krcmar, 2013). Rezultati istraživanja nedvosmisleno potvrđuju da su deca predškolskog uzarsta verni korisnici računarskih softvera (Judge et al., 2015; Orfanakis \& Papadakis, 2014), da uživaju u korišćenju sve većeg spektra računarskih igara (Plowman et al., 2010) koje su najzastupljeniji izbor aktivnosti u slobodnom vremenu (Cherney \& London, 2006). Vaspitači i roditelji dece uzrasta od 3 do 6 godina koriste računarske igre za učenje, zabavu, samostalnu igru dece i igru sa vršnjacima (Anand \& Krosnick, 2005) kako bi produkte tehnologije stavili u službu podsticanja razvoja dece predškolskog uzrasta. Računarski alati imaju funkciju unapređivanja dečijeg razvoja samo onda kada se koriste kao obrazovni alat i sredstvo koje omogućava učenje dece kroz vođenu interakciju, istraživanje i kreativno rešavanje problema (Clements \& Samara, 2003). Porast vremena koje deca predškolskog uzrasta provode igrajući računarske igre nameće potrebu za ispitivanjem efekata digitalne tehnologije na život i razvoj dece. Dizajn računarskih igara mora biti brižljivo osmišljen kako bi se sprečili negativni uticaji na decu ranog uzrasta (Höysniemi et al., 2003).

Računarske igre, kao integralni deo života modernog društva, neprestano proširuju opseg svojih konzumenata i vernih korisnika. Vreme koje deca ranog uzrasta provode ispred monitora računara (Anderson \& Pempek, 2005) igrajući računarske igre u porodičnom ambijentu i predškolskoj ustanovi je u kontinuiranom porastu (Korečko i Sobota, 2017), te se nameće potreba za ispitivanjem efekata računarskih igara kako bi se benefiti upotrebe stavili u službu razvoja dece predškolskog uzrasta, a neželjene posledice svele na minimum. Očekivanja da se deca mogu u potpunosti izolovati od modernih digitanih alata, a samim tim i računarskih igara, daleko su od realnosti, budući da su sve pore društva protkane informaciono-komunikacionim tehnologijama (Gligora-Marković et al., 2013). Kao ključna komponenta pravilne upotrebe računarskih igara navodi se pre svega primerenost razvoju i mogućnostima dece predškolskog uzrasta, a nakon toga adekvatno uključivanje odraslih kao osoba koje usmeravaju, prate i regulišu proces igranja (Lazić, 2014). U pravu dece da postanu kompetentni korisnici tehnologija stoji obaveza društva da im omogući uslove da razvijaju svoju digitalnu pismenost. Kompjuterska pismenost na ranom uzrastu nosi određene specifičnosti, iako je u određivanju prošla isti put kao i kompjuterska pismenost odraslih (Pribišev-Beleslin, 2010).

Računarske igre je na dečijem uzrastu moguće raznovrsno koristiti, sa ciljem da dete nešto nauči ili sa ciljem da se na razne načine razonodi. Deca mogu da koriste računarske igre i uporedo razvijaju širok spektar veština i znanja - uče o slovima, brojevima, oblicima, bojama i ritmu (Dhingra et al., 2009). Početkom 80-ih godina računari su postali dostupni u mnogim vrtićima, a tokom devedesetih godina 20 . veka primećuje se veće napredovanje na polju izrade računarskih igara i progarama za predškolski uzrast. Sa većom dostupnošću digitalnih alata i lakoćom njihove upotrebe razvijaju se računarske igre za decu predškolskog uzrasta, a mogućnosti 
da se one koriste postaju sve veće. U malim grupama dece računarske igre podstiču vršnjačko učenje, bogatiju komunikaciju, razmenu ideja i deljenje saveta, otkrića i iskustava sa drugima. Deca daju konkretna i precizna objašnjenja drugoj deci, više vole da rade u malim timovima i razvija se osećaj samopoštovanja i zadovoljstva svojim uspehom. Potreba dece i motivacija za korišćenjem računarskih igara prvi je dokaz da je predškolski period vreme kada treba početi sa upotrebom digitalne tehnologije u vaspitno-obrazovnom radu (Lazić, 2014).

Rezultati istraživanja potvrđuju pozitivan uticaj digitalnih medija i računarskih igara na socijalni, psihološki, kognitivni razvoj, proces učenja dece predškolskog uzrasta (Din \& Caleo, 2000), učenje maternjeg i stranog jezika, pisanja i čitanja (Lieberman et al., 2009). Sa druge strane, rasprave o negativnim uticajima savremenih medija, a posebno računarskih igara predstavljaju najnovije manifestacije tradicionalnog shvatanja savremenih medijskih koncepata. Jasno je da postoji opšta atmosfera zabrinutosti zbog štetnih uticaja računarskih igara na decu ranog uzrasta, a u fokusu te zabrinutosti nalaze se pretežno duhovna i moralna načela (Drašković, 2011: 47). U našoj sredini se još uvek vode diskusije oko toga da li deca treba da koriste računarske igre (Plowman et al., 2010), te postoji misljenje da je ,računar štetan za decu". Prihvatajući to tek tako, mnogi vaspitači izbegavaju bilo kakvu primenu računarskih aplikacija u aktivnostima koje obavljaju u vaspitno-obrazovnom radu (Janković i Dmitrić, 2011).

Lazić (2014) ističe da se pozitivni efekti korišćenja računarskih igara mogu uočiti u sledećim oblastima razvoja: intelektualni razvoj, razvoj govora, motivacija, gotovost za školsko obrazovanje, odnosno, čitanje, pisanje i početni matematički pojmovi, kreativnost, saradnja i komunikacija. Međutim, on navodi i područja gde se mogu izdvojiti faktori rizika: fizičko i mentalno zdravlje dece, rizici za socijalni i emotivni razvoj i rizici za intelektualni razvoj i kreativnost. Na razvoj i učenje dece posebno negativan uticaj mogu imati razvojno neprilagođeni načini primene (Lazić, 2014: 404-409). Benefiti korišćenja digitalnih alata mogu se uspešno integrisati u proces vaspitanja i obrazovanja, a igranje računarskih igara se ne mora nužno doživljavati kao gubljenje vremena. Danas, računarske igre imaju sadržaje iz različitih oblasti (poput matematičkih pojmova, upoznavanja okoline i razvoja govora) i motivišu decu da saznaju više o ovim temama (Olsen, 2011). Da bi se utvrdili efekti računarskih igara na razvoj dece predškolskog uzrasta potrebno je angažovanje stručnjaka i sprovođenje empirijskih studija. Naročito značajnim smatra se ispitivanje stavova vaspitača, budući da su oni u direktnom kontaktu sa decom-korisnicima računarskih aplikacija (Wood et al., 2008). Pri upotrebi računarskih igara deca predškolskog uzrasta se ne mogu osloniti na sopstvenu procenu adekvatnosti sadržaja koje koriste igrajući se. Upravo zbog toga je neophodno da vaspitači i roditelji uz primenu novih medijskih tehnologija u svet digitalnog obrazovanja decu uvode postepeno i brižljivo osmišljeno (Marinović, 2002).

Primena računarskih igara ima pozitivne i negativne uticaje na sve oblasti razvoja dece predškolskog uzrasta. Autor Hristov (Hristov i sar., 2013: 6-9) detaljno navodi potencijalne uticaje na sve oblasti dečijeg razvoja. U domenu fizičkog razvoja autor kao pozitivne efekte navodi razvijanje muskulature šake i razvoj koordina- 
cije oka i ruke, dok kao potencijalni negativni uticaj navodi nerazvijenost mišića. U oblasti socioemocionalnog razvoja izdvaja se unapređenje društvenih interakcija, razvoj kooperativnosti i svesti o sebi i drugima, a u oblasti kognitivnog razvoja razvoj mišljenja, koncentracije i pažnje, kao pozitivan efekat primene računarskih igara u predškolskom uzrastu.

Interaktivnost je ključan uslov koji moraju zadovoljiti računarske igre da bi imale pedagoškog potencijala i ostvarile pozitivne efekte na razvoj dece predškolskog uzrasta. Takođe, nivo efikasnosti primene računarskih igara nije isti u svim oblastima, te se ne može izvesti zaključak da se računarske igre mogu uspešno primeniti na svaku oblast, uzrast i okruženje (Stanisavljević Petrović i Pavlović, 2017).

\section{Zaključak}

Predškolski uzrast je period života koji ostavlja značajne implikacije na celokupan kasniji razvoj deteta. Kvalitet vaspitno-obrazovnog postupanja u ovom periodu, kako u porodičnom okruženju tako i u predškolskoj ustanovi utiče na sliku koju dete kreira o sebi, na odnos prema vršnjacima i članovima porodice. Istaknut značaj predškolskog uzrasta obavezuje na pedagošku nužnost naučnog ispitivanja svih metoda, sredstava i oblika rada koji se u periodu pre polaska u školu primenjuju u radu sa decom.

Analizom literature $\mathrm{u}$ oblasti digitalne tehnologije u obrazovanju ustanovljeno je da se u poslednjim decenijama korišćenje tehnologije u vrtićima i u radu sa decom predškolskog uzrasta značajno povećalo. Naučno-tehnološka revolucija inicirala je veliki broj istraživanja koja su se bavila vaspitno-obrazovnom vrednošću različitih digitalnih alata, među kojima su najzastupljenije računarske igre. Rezultati teorijskog proučavanja pokazuju da se potencijal računarskih igara ogleda u činjenici da one nemaju kao inicijalni cilj zabavu i razonodu dece već usvajanje kompleksa novih informacija i razvoj digitalne pismenosti koja je u modernom dobu neophodna. Pored toga, prednost računarskih igara jeste to što se mogu primeniti u gotovo svim oblastima i na svim nivoima obrazovanja. Dominacija računarskih igara u radu sa decom predškolskog uzrasta može se objasniti činjenicom da one angažuju misaone procese i motivišu decu da ulože intelektualni napor da bi postigla uspeh, a pored toga obezbeđuju deci sticanje znanja na spontan, zabavan, zanimljiv način.

Imajući u vidu sve značajnije prisustvo računarskih igara u svakodnevnom životu, razvoju i učenju dece predškolskog uzrasta neophodno je kontinuirano ispitivati tematiku edukativnih računarskih igara i njihovih pedagoških potencijala, posebno na našem području koje i dalje ima konzervativan pristup kada je u pitanju inoviranje vaspitno-obrazovnog rada primenom modernih digitalnih medija. Naročito značajnim smatra se digitalno opismenjavanje vaspitača i unapređivanje njihovih kompetencija za primenu digitalnih alata, koje mora biti u skladu sa suštinskom odlikom savremenog društva koja se kreće u pravcu sve veće digitalizacije. 


\section{Literatura}

Arsović, B. B. i Zlatić, L. Đ. (2017). Računarske video-igre kao obrazovni medij u mlađem uzrastu - prednosti i nedostaci. U: C. Marinković (ur.). Zbornik radova, 20(19), (225-236). Pedagoški fakultet u Užicu: Snežana Marinković.

Anand, S. \& Krosnick, J. (2005). Demographic predictors of media use among infants, toddlers, and preschoolers. American Behavioral Scientist, 48(5), 539-561.

Anderson, D. R. \& Pempek, T. A. (2005). Television and very young children. American Behavioral Scientist, 48, 505-522.

Andevski, M. i Arsenijević, J. (2011). Kompetencije vaspitača za upotrebu novih medija i tehnologija. U: T. Grujić (ur). Zbornik VŠSSOV, 6(2), (25-35). Kikinda: Visoka škola strukovnih studija za obrazovanje vaspitača u Kikindi.

Anđelić, S. i Milosavljević, G. (2007). Nove informacione tehnologije u obrazovanju dece. Infoteh jahorina, 6(8), 494-498. Sarajevo: Univerzitet u Istočnom Sarajevu, Elektrotehnički fakultet. Retrived from: https://infoteh.etf.ues.rs.ba/zbornik/2007/index.htm

Anđelković, N. (2008). Informaciona tehnologija u predškolskom vaspitanju i obrazovanju. U: D. Golubović (ur). Zbornik radova Tehnika i informatika u obrazovanju 8 , (65-70). Čačak: Tehnički fakultet Čačak.

Cherney, I. D. \& London, K. (2006). Gender-linked differences in the toys, television shows, computer games, and outdoor activities of 5-to 13-year-old children. Sex Roles, 54(9-10), 717.

Cingel, D. P. \& Krcmar, M. (2013). Predicting media use in very young children: The role of demographics and parent attitudes. Communication Studies, 64(4), 374-394.

Clements, D. H. (2002). Computers in early childhood mathematics. Contemporary Issues in Early Childhood, 3(2), 160-181.

Clements, D. H., Nastasi, B. K. \& Swaminathan, S. (1993). Research in review. Young children, 56-64. Retrived from: https://www.researchgate.net/profile/

Douglas_Clements/publication/234586711_Young_Children_and_Computers Crossroads and Directions from Research Research in Review/ links/00b7d534efd2d2ae36000000.pdf

Clements, D.H. \& Samara, J. (2003). Young children and Technology: What does the research say?. Young Children, 58(6), 34-40.

Dhingra, R., Sharma, N. \& Kour, M. (2009). Relationship between parental perception and young childrens' usage of computers. Journal of Human Ecology, 28(3), 167-170.

Din, F. S. \& Caleo, J. (2000). Playing Computer Games Versus Better Learning. Paper presented at the Annual Conference of the Eastern Educational Research Association, Clearwater, Florida, 16-19 February. Retrived from: https://files.eric.ed.gov/ fulltext/ED438905.pdf

Drašković, M. (2011). Uticaj medija na djecu ranog uzrasta sa posebnim osvrtom na računalne igre. Medijski dijalozi, 4(1), 45-56.

Gligora-Marković, M., Antić, M. i Rauker Koch, M. (2013). Proces razvoja multimedijske računalne igre. U: S. Hirning, M. Gligora Marković i E. Ribarić Čučković (ur.). 
Zbornik Veleučilišta u Rijeci, 1(1), (151-163). Rijeka: Veleučilište u Rijeci.

Griffiths, M. D. (2002). The educational benefits of videogames. Education and health, 20(3), 47-51.

Höysniemi, J., Hämäläinen, P. \& Turkki, L. (2003). Using peer tutoring in evaluating the usability of a physically interactive computer game with children. Interacting with computers, 15(2), 203-225.

Hristov, R., Kaevik, Z., Gelev, S., \& Hristova, S. (2013). Нови образовни технологии за деца од предучилишна возраст. Retrived from:

http://games.xboltz.net/CIS107_honors_paper.pdf

http://www.ftn.kg.ac.rs/konferencije/tio6/radovi/3)\%20Nastavnici\%20i\%20skola $\% 20$ u\%20informaciono-tehnoloskom\%20okruzenju/PDF/304\%20Marina\%20Jankovic. pdf

http://www.marcprensky.com/writing/Prensky\%20-\%20Ch2-Digital\%20Game-Based\%20Learning.pdf

https://www.researchgate.net/publication/249963087_Novi_obrazovni_tehnologii_za deca_od preducilisna_vozrast

Janković, M. i Dmitrić, Lj. (2011). Primena računara u pripremnom predškolskom programu. U: D. Golubović (ur.). Tehnologija, Informatika i Obrazovanje, 6, (65-70). Čačak: Tehnički fakultet Čačak. Retrived from:

Judge, S., Floyd, K. \& Jeffs, T. (2015). Using mobile media devices and apps to promote young children's learning. In: K. Heider \& M. Renck-Jalongo (eds.). Young children and families in the information age. Educating the young child, (117-131). Netherlands: Springer.

Korečko, Š. i Sobota, B. (2017). Computer games as Virtual Environments for Safety-Critical Software Validation. JIOS, 41(2), 197-212.

Lazić, V. (2014). Dečije igre u kompjuterskoj kulturi. U: I. Milićević (ur). Zbornik radova Tehnika i informatika u obrazovanju 29-712(11), (404-409). Čačak: Tehnički fakultet Čačak.

Lieberman, D. A., Bates, C. H. \& So, J. (2009). Young children's learning with digital media. Computers in the Schools, 26(4), 271-283.

Marinović, M. (2002). Computers in Preschool institutions: students‘ attitudes. In MIPRO 2002. Retrived from: https://bib.irb.hr/datoteka/405611.MIPRO02.pdf

Marsh, J. (2010). Young children's play in online virtual worlds. Journal of early childhood research, 8(1), 23-39.

Mikelić Preradovic, N., Lešin, G. i Šagud, M. (2016). Investigating Parents‘ Attitudes towards Digital Technology Use in Early Childhood: A Case Study from Croatia. Informatics in Education, 15(1), 127-146.

Nikolopoulou, K., Gialamas, V. \& Batsouta, M. (2010). Young children's access to and use of ICT at home. Review of Science, Mathematics and ICT Education, 4(1), 25-40.

Olsen, P. (2011). Computer games: enhancing education. Honors Project, CIS107, Electronic Game Industry, Mesa Community College. Retrived from: 
Orfanakis, V. \& Papadakis, S. (2014). A new programming environment for teaching programming. A first acquaintance with Enchanting. In Proceedings of the 2nd international virtual Scientific Conference Scieconf, (268-273). Slovakia: EDIS - Publishing Institution of the University of Zilina. Retrived from: file:///C:/Users/anast/ Downloads/Anewprogrammingenvironmentforteachingprogramming.AfirstacquaintancewithEnchanting..pdf

Papadakis, S. (2018). The use of computer games in classroom environment. Int. J. Teach. Case Stud, 9(1),1-25.

Paraskeva, F., Mysirlaki, S. \& Papagianni, A. (2010). Multiplayer online games as educational tools: Facing new challenges in learning. Computers \& Education, 54, 498-505.

Pavlović, D. i Mihajlov-Prokopović, A. (2015). Attitudes of teachers to the application of computers in preschools. In: I. Roceanu, L. Ciolan, C. Holotescu, C. Radu, I. Stănescu \& B. Logofatu (eds.). Proceedings of the 11th International Scientific Conference "eLearning and Software for Education": Rethinking education by leveraging the eLearning pillar of the Digital Agenda for Europe (211-283). Bucharest: Carol I NDU Publishing House, 1.

Peirce, N. (2013). Digital game-based learning for early childhood. Dublin, Ireland: Learnovate Centre.

Plowman L, McPake, J. \& Stephen, C. (2010). The technologisation of childhood? Young children and technology in the home. Children and Society, 24(1), 63-74.

Plowman, L. \& Stephen, C. (2003). A 'benign addition'? Research on ICT and preschool children. Journal of computer assisted learning, 19(2), 149-164.

Prensky, M. (2001). Digital natives, digital immigrants part 1. On the horizon, 9(5), 1-6.

Prensky, M. (2001). The games generations: How learners have changed. In Prensky, M. (Ed.), Digital game-based learning, 35-51. New York, NY: McGraw-Hill. Retrived from:

Prensky, M. (2007). Computer games and learning: digital game-based learning. Retrived from: https://s3.amazonaws.com/academia.edu.documents/6851163/computer_games and learning 2006.pdf?AWSAccessKeyId=AKIAIWOWYYGZ2Y53 UL3A\&Expires $=1544270728 \&$ Signature $=\mathrm{hxdT350HF6gx} \% 2 \mathrm{FZfZBm} 1$ Ad8nOIa U\%3D\&response-content-disposition $=$ inline $\% 3 \mathrm{~B} \% 20$ filename $\% 3$ DComputer games and learning Digital game.pdf

Pribišev-Beleslin, T. (2010). Rana kompjuterska pismenost: Mogućnosti i rizici za razvoj i učenje djece predškolskog uzrasta, Okrugli sto: Kako zaštiti djecu na internetu. Ombusdman za djecu Republike Srpske. Banja Luka: Univerzitet u Banja Luci, Filozofski fakultet. Retrived from: http:/www.djeca.rs.ba/uploaded/Rana\%20kompjuterska $\% 20$ pismenost $\% 20$ rad.pdf

Radovanović, V. i Karić, J. (2011). Stavovi nastavika prema primeni informacionih i komunikacionih tehnologija u školama za gluve i nagluve. Specijalna edukacija i rehabilitacija, 10(1), 37-48.

Rideout, V. J., Vandewater, E. A. \& Wartella, E. A. (2003). Zero to Six: Electronic media in the lives of infants, toddlers and preschoolers. Washington, DC: The Henry J. Kaiser Family Foundation.

Savanović, N., Šarac, M., Stamenković, D., i Adamović, S. (2016). Unreal Engine plat- 
forma za razvoj edukativnih video igara. Zbornik radova univerziteta sinergija, 1(1), (ur.) Talijan, G., 118-121. Bijeljina: NULRS.

Stanisavljević Petrović, Z. i Pavlović, D. (2017). Novi mediji u ranomm obrazovanju. Niš: Filozofski fakultet Univerziteta u Nišu.

Subrahmanyam, K., Greenfield, P., Kraut, R. \& Gross, E. (2001). The impact of computer use on children's and adolescents' development. Journal of Applied Developmental Psychology, 22(1), 7-30.

Vandewater, E. A., Rideout, V. J., Wartella, E. A., Huang, X., Lee, J. H. \& Shim, M. S. (2007). Digital childhood: electronic media and technology use among infants, toddlers, and preschoolers. Pediatrics, 119(5), 1006-1015.

Vasiljevic, I., Bjelica, D., Popovic, S. i Gardasevic, J. (2015). A critical review of parents of preschool children related to computer use. Journal of Physical Education and Sport, 15(4), 692-696.

Veličković, S. (2014). Edukacija vaspitača za primenu IKT u vrtiću. Sinteza, Univerzitet Singidunum, 375-378.

Verenikina, I., Harris, P. \& Lysaght, P. (2003). Child's play: computer games, theories of play and children's development. In: J. Wright, A. McDougall, J. Murnane, J. Lowe (eds.). Proceedings of the international federation for information processing working group 3.5 open conference on Young children and learning technologies-34, (99-106). Sydney, Australia: Australian Computer Society, Inc..

Wood, E., Specht, J., Willoughby, T. \& Mueller, J. (2008). Integrating computer technology in early childhood education environments. The Alberta Journal of Educational Research, 54(2), 210-226.

Wu, C. S. T., Fowler, C., Lam, W. Y. Y., Wong, H. T., Wong, C. H. M. \& Loke, A. Y. (2014). Parenting approaches and digital technology use of preschool age children in a Chinese community. Italian journal of pediatrics, 40(1), 44.

\title{
COMPUTER GAMES IN THE EDUCATIONAL WORK OF PRESCHOOL INSTITUTIONS
}

\author{
Anastasija Mamutović \\ University of Niš, Faculty of Philosophy in Niš, Department of Pedagogy
}

Abstract: The last decades of the 20th century are characterized by dynamic deve-
lopment and the spread of innovative digital media. These digital tools are successi-
vely appearing and they find application in all domains of human life and work, by
changing the structure and character of educational activities. Prior to the direct imple-
mentation of digital media in the work of preschool institutions, it will be constantly
approaching the realization of both theoretical and empirical research in their pedago-
gical value. The aim of these studies is to arrive at scientific data that will be used for
the development of preschool children and improving the level of their digital literacy.
The aim of this paper is to point out the educational potential of computer games in 
working with pre-school children with the theoretical analysis of the effects of digital media on development, behavior and learning. The polarized viewpoints of many authors are also considered and the argumentation that is at the basis of their views is considered. The results of the theoretical analysis point to the necessity of a continuous examination of the themes of educational computer games and their pedagogical potentials, especially in our field which still has a conservative approach when it comes to innovating educational work using modern digital media.

Key words: computer games, pre-school institutions, educational work.

\section{Citiranje članka:}

Mamutović, A. (2018). Računarske igare u vaspitno-obrazovnom radu predškolskih ustanova. Godišnjak za pedagogiju, 3(2), 91-102. 